\title{
ANALISIS TARIF ANGKUTAN UMUM JURUSAN PALANGKA RAYA - PONTIANAK
}

\author{
. Maretina Eka Sinta \\ Program Studi Teknik Sipil, Fakultas Teknik, Universitas Kristen Palangka Raya \\ E mail : inamaretina@yahoo.com
}

\begin{abstract}
ABSTRAK
Kalimantan Barat khususnya Pontianak, pada saat ini menekankan pada bidang transportasi darat. Pembangunan jalan mendapatkan prioritas terbesar. Hal ini dilakukan mengingat masih banyak daerah-daerah terpencil yang belum terjangkau oleh jaringan jalan yang ada. Dengan adanya jalur darat tersebut maka arus barang dan orang akan semakin banyak, hal ini membuka peluang akan jasa angkutan umum yang melayani jalur dari Palangka Raya menuju Pontianak. Penelitian ini dilakukan dengan cara survei lapangan, pengambilan data dibagi menjadi dua yaitu data primer dan sekunder. Penelitian ini bertujuan untuk mengetahui besarnya biaya operasional kendaraan angkutan umum jurusan Palangka Raya menuju Pontianak dan untuk mengetahui tarif ideal penumpang angkutan umum jurusan Palangka Raya Pontianak yang sesuai dengan biaya operasional yang dikeluarkan. Tarif umum angkutan jurusan Palangka Raya - Pontianak yang berlaku pada saat penelitian sekarang adalah sebesar Rp. 900.000,00 org/rit. Dengan tarif umum Rp. 900.000,00 org/rit, dan tarif dasar Rp. 464.298,56org/rit maka memberikan keuntungan bagi pengusaha angkutan sebesar Rp. 435.701,44 rit/org atau sekitar 49\%. Sehingga memberikan keuntungan yang layak bagi pengelola angkutan umum jurusan Palangka Raya - Pontianak.
\end{abstract}

\section{Kata Kunci : tarif, angkutan, biaya operasional}




\section{PENDAHULUAN}

Provinsi Kalimantan Tengah sebagai sebuah daerah dengan sumber daya alam yang melimpah dan belum tergali,memerlukan sarana dan prasarana yang memadai sehingga dapat membantu kelancaran sumber daya alam tersebut. Salah satu faktor yang sangat vital dan berperan besar adalah sarana dan prasarana transportasi.

Kalimantan Barat khususnya Pontianak, pada saat ini pembagunan transportasi lebih ditekankan pada bidang transportasi darat. Pembangunan jalan mendapatkan prioritas terbesar. Dengan adanya jalur darat tersebut maka arus barang dan orang akan semakin banyak,hal ini membuka peluang akan jasa angkutan umum yang melayani jalur dari Palangka Raya menuju Pontianak

Tujuan Penelitian ini adalah mengetahui besarnya biaya operasi kendaraan angkutan umum jurusan Palangka Raya menuju Pontianak dan untuk mengetahui tarif ideal penumpang angkutan umum jurusan Palangka Raya Pontianak yang sesuai dengan biaya operasional yang dikeluarkan.

\section{METODE PENELITIAN}

\section{Metode Pengumpulan Data}

Dalam penelitian ini dilakukan dengan cara survey lapangan menggunakan metode penentuan sampel tak acak (Now Random Sampling). Untuk pengambilan data (survey)dalam penelitian ini dibagi menjadi 2 yaitu :

1. Data Primer, meliputi data yang perhitungan biaya operasi kendaraan (meliputi data servis, data ganti ban,data perawatan body,data biaya cuci mobil dan upah operator), data penghasilan yang didapatkan dalam suatu hari (trayek PP) dan data jumlah penumpang/hari.

2. Data Sekunder, dalam penelitian ini meminta data ke Dinas Perhubungan Provinsi Kalimantan Tengah yang mana data tersebut ada dan lengkap diberikan untuk proses penelitian. Adapun data dalam penelitian ini data sekunder yang diperlukan adalah data harga kendaraan, jarak tempuh, jumlah Armada, pajak kendaraan /STNK

\section{Analisa Data}

Langkah-langkah yang dilakukan dalam menganalisa data tersebut adalah sebagai berikut :

a. Mengolah data yang telah diperoleh dari survey dilapangan.

b. Menghitung data biaya operasi kendaraan yang diperoleh dengan metode pendekatan biaya per kilo meter yang dikeluarkan oleh kendaraan,

c. Menghitung total biaya pokok per hari kendaraan,yaitu dengan mengalikan BOK per kilo meter dengan jarak.

d. Total biaya pokok yang dibagi dengan jumlah penumpang harian minimum yang representative,sehingga didapatkan tariffpokok rupiah per satu kali pengakutan

e. Menghitung tarif dasar yaitu merupakan hasil perkalian antara tarif pokok dan jarak (kilo meter)rata-rata satu hari dan ditambah $10 \%$ untuk keuntungan pengelola/pemilik kendaraan angkutan.

f. Dari hasil analisa ini,nantinya akan diperoleh besarnya BOK yang dikeluarkan oleh penyedia jasa per kilo meter.

\section{Biaya Retribusi}

Berdasarkan Direktorat Jendral Perhubungan Darat, Keputusan Direktorat Jendral Darat Nomor SK.687/AJ.206/DRJD/2002, komponen biaya operasi kendaraan yang akan dihitung sebagai berikut:

\section{1) Biaya Penyusutan Kendaraan Per km}

Selama suatu alat dipakai harus dianggap nilainya berkurang/menyusut dan dibutuhkan suatu biaya untuk menutupi suatu biaya untuk menutupi suatu alat tidak berdaya guna,yakni biaya penyutusan. Maka begitu alat tidak berdaya guna lagi, saat itu pula sudah tersedia biaya sebagai pengganti alat tersebut yang sudah dikumpulkan selama umur pemakain alat.

Biaya penyusutan di hitung dengan rumus :

$$
\text { penyusutan }=\frac{\text { harga kendaraan }- \text { nilai residu }}{\text { prod. kond }-\frac{\mathrm{km}}{\mathrm{th}} \times \text { masa penyusutan }}
$$


Nilai residu kendaraan $20 \%$ dari harga kendaraan.

\section{2) Biaya Bahan Bakar Minyak (BBM)per km}

penyusutan $=\frac{\text { biayapemakaianBBMkendaraanperhari }}{\mathrm{km} \text { tempuhperhari }}$

\section{3) Biaya Ban per $\mathrm{km}$}

Biaya yang dikeluarkan untuk pembelian ban

Biaya ban dapat dihitung dengan rumus :

biaya ban $=\frac{\text { jumlah pemakaian ban } \mathrm{x} \text { harga ban per buah }}{\text { bmana }}$

\section{4) Biaya Servis Kecil per km}

Servis kecil dilakukan dengan patokan kilometer tempuh antar servis besar,yang pada dasarnya penggatian oli bensin dan penambahan gemuk serta minyak rem.

Biaya servis kecil dihitung dengan rumus :

biayaserviskecil $=\frac{\text { biayaolimesin }+ \text { gemuk+minyakrem }}{\text { kmserviskecil }}(3.4)$

\section{5) Biaya Servis Besar per km}

Servis besar dilakukan setelah beberapa kali servis kecil,atau dengan patokan kilometer tempuh.

Biaya servis dapat dihitung dengan rumus :

$$
\text { servis besar }=\frac{\begin{array}{l}
\text { biaya oli mesin }+ \text { kampas kopling }+ \\
\text { minyak rem }+ \text { kampas rem }+ \text { gir }+ \text { busi }
\end{array}}{\mathrm{km} \text { servis besar }}
$$

\section{6) Biaya KampasKopling per km}

Biaya ini dihitung dengan rumus :

$$
\text { biaya kampas rem }=\frac{\text { harga kampas kopling }}{\text { km kampas kopling }}
$$

\section{7) Biaya Kampas Rem per km}

Biaya ini dihitung dengan rumus :

$$
\text { biaya kampas rem }=\frac{\text { harga kampas rem }}{\text { km kampas rem }}
$$

\section{8) Biaya Retribusi per km}

Biaya ini dihitung dengan rumus :

$$
\text { biaya retribusi }=\frac{\text { retribusi per hari }}{\text { prod } \mathrm{km} \text { kend per hari }}
$$

\section{9) Biaya STNK/Pajak Kendraan per km}

Biaya ini dihitung dengan rumus :

biaya pajak kendaraan $=\frac{\text { biaya STNK per tahun }}{\text { prod } \mathrm{km} \text { kend per tahun }}$

10) Biaya Cuci Kendraan per km

Biaya dihutung dengan rumus :

biayacucikendaraan $=\frac{\text { biayacucimobilper bulan }}{\text { prodkmkendbulan }}(3.10)$

\section{Bagan Aliran Penelitian}

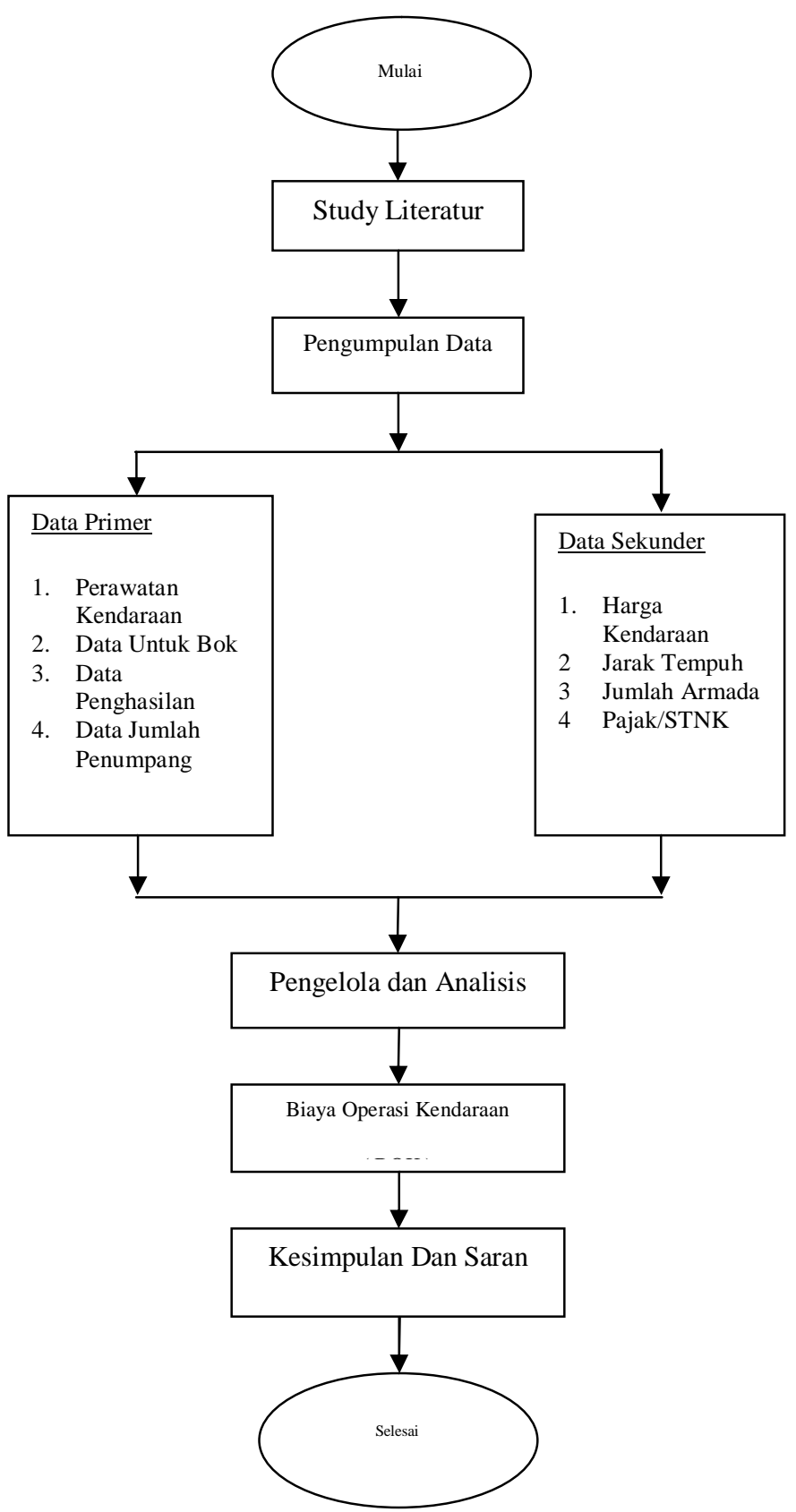

Gambar 3.1 Bagan Alir Penelitian 


\section{HASIL DAN PEMBAHASAN}

Langkah-langkah yang dilakukan dalam menganalisa data tersebut adalah sebagai berikut :

g. Mengolah data yang telah diperoleh dari survey dilapangan.

h. Menghitung data biaya operasi kendaraan yang diperoleh dengan metode pendekatan biaya per kilo meter yang dikeluarkan oleh kendaraan,

i. Menghitung total biaya pokok per hari kendaraan,yaitu dengan mengalikan BOK per kilo meter dengan jarak.

j. Total biaya pokok yang dibagi dengan jumlah penumpang harian minimum yang representative,sehingga didapatkan tariff pokok rupiah per satu kali pengakutan

k. Menghitung tarif dasar yaitu merupakan hasil perkalian antara tarif pokok dan jarak (kilo meter)rata-rata satu hari dan ditambah $10 \%$ untuk keuntungan pengelola/pemilik kendaraan angkutan.

1. Dari hasil analisa ini,nantinya akan diperoleh besarnya BOK yang dikeluarkan oleh penyedia jasa per kilo meter.

\section{Biaya Retribusi}

Berdasarkan Direktorat Jendral Perhubungan

Darat, Keputusan Direktorat Jendral Darat Nomor

SK.687/AJ.206/DRJD/2002, komponen biaya operasi kendaraan yang akan dihitung sebagai berikut:

\section{1) Biaya Penyusutan Kendaraan Per km}

Selama suatu alat dipakai harus dianggap nilainya berkurang/menyusut dan dibutuhkan suatu biaya untuk menutupi suatu biaya untuk menutupi suatu alat tidak berdaya guna,yakni biaya penyutusan. Maka begitu alat tidak berdaya guna lagi, saat itu pula sudah tersedia biaya sebagai pengganti alat tersebut yang sudah dikumpulkan selama umur pemakain alat.

Biaya penyusutan di hitung dengan rumus :

$$
\text { penyusutan }=\frac{\text { harga kendaraan }- \text { nilai residu }}{\text { prod. kond }-\frac{\mathrm{km}}{\mathrm{th}} \times \text { masa penyusutan }}
$$

Nilai residu kendaraan $20 \%$ dari harga kendaraan.

\section{Biaya Bahan Bakar Minyak (BBM)per km}

$$
\text { penyusutan }=\frac{\text { biaya pemakaian BBM kendaraan per hari }}{\mathrm{km} \text { tempuh per hari }}
$$

\section{Biaya Ban per km}

Biaya yang dikeluarkan untuk pembelian ban

Biaya ban dapat dihitung dengan rumus :

$$
\text { biaya ban }=\frac{\text { jumlah pemakaianban } \mathrm{xharga} \text { ban per buah }}{\text { km daya tahan ban }}
$$

\section{Biaya Servis Kecil per $\mathbf{k m}$}

Servis kecil dilakukan dengan patokan kilometer tempuh antar servis besar,yang pada dasarnya penggatian oli bensin dan penambahan gemuk serta minyak rem.

Biaya servis kecil dihitung dengan rumus :

$$
\text { biaya servis kecil }=\frac{\text { biaya oli mesin }+ \text { gemuk }+ \text { minyak rem }}{\mathrm{km} \text { servis kecil }}
$$

\section{Biaya Servis Besar per km}

Servis besar dilakukan setelah beberapa kali servis kecil, atau dengan patokan kilometer tempuh. 
Biaya servis dapat dihitung dengan rumus :

$$
\text { servis besar }=\frac{\begin{array}{l}
\text { biaya oli mesin }+ \text { kampas kopling }+ \\
\text { minyak rem }+ \text { kampas rem }+ \text { gir }+ \text { busi }
\end{array}}{\text { km servis besar }}
$$

\section{Biaya Kampas Kopling per km}

Biaya ini dihitung dengan rumus :

$$
\text { biaya kampas rem }=\frac{\text { harga kampas kopling }}{\mathrm{km} \text { kampas kopling }}
$$

\section{Biaya Kampas Rem per km}

Biaya ini dihitung dengan rumus :

$$
\text { biaya kampas rem }=\frac{\text { harga kampas rem }}{\text { km kampas rem }}
$$

\section{Biaya Retribusi per $\mathrm{km}$}

Biaya ini dihitung dengan rumus :

$$
\text { biaya retribusi }=\frac{\text { retribusi per hari }}{\text { prod } \mathrm{km} \text { kend per hari }}
$$

\section{Biaya STNK/Pajak Kendraan per km}

Biaya ini dihitung dengan rumus :

biaya pajak kendaraan $=\frac{\text { biaya STNK per tahun }}{\text { prod km kend per tahun }}$

\section{Biaya Cuci Kendraan per km}

Biaya dihutung dengan rumus :

$$
\text { biaya cuci kendaraan }=\frac{\text { biaya cuci mobil per bulan }}{\text { prod } \mathrm{km} \text { kend bulan }}
$$

\section{HASIL DAN PEMBAHASAN}

\section{Perhitungan Biaya Operasi Kendaraan}

Perhitungan biaya operasional kendaraan dilakukan untuk mengetahui biaya pokok yang dikeluarkan untuk produksi kendaraan. Pada perhitungan biaya operasional kendaraan beberapa hal yang perlu diperhatikan adalah sebagai berikut : a. Karakteristik kendaraan :

Jenis Kendaraan : Kendaraan roda empat Spesifikasi tempat duduk : Tempat duduk penumpang di depan, Tengah, dan belakang Spesifikasi jumlah ban : 4 buah ban (Ban depan dua, ban belakangdua)

Kapasitas Kendaraan : 6 orang (1 pengemudi, 5 penumpang)

b. Produksi Kendaraan :

$$
\begin{array}{ll}
\text { Km tempuh / hari } & : 1011 \mathrm{~km} \\
\text { Hari operasional / bulan } & : 5 \text { hari } \\
\text { Km tempuh / bulan } & : 5,055 \mathrm{~km} \\
\text { Km tempuh / tahun } & : 60,66 \mathrm{~km}
\end{array}
$$

Dari data survei yang dilakukan, maka perhitungan biaya operasi kendaraan angkutan umum jurusan Palangka Raya - Pontianak adalah sebagai berikut :

\section{Biaya penyusutan (depresiasi)}

Biaya penyusutan dalam studi ini menggunakan metode garis lurus (Straight Line Methods). Langkah-langkah perhitungan menggunakan rumus sebagai berikut :

Harga awal kendaraan =Rp. 240.000.000,00

Umur ekonomis $\quad=5$ tahun

Nilai residu

$$
=\text { Rp. } \quad 48.000 .000,00 \quad(20 \%
$$
dari harga Kendaraan )

$$
\begin{aligned}
\text { Penyusutan } & =\frac{\text { Rp. } 240.000 .000,00-\text { Rp. } 48.000 \cdot 000,00}{5} \\
& =\text { Rp. } 38.400 .000,00
\end{aligned}
$$

Harga Penyusutan/kend/Km $=\underline{\text { penyusutan kend/th }}$ 
Analisis Tarif Angkutan Umum..., MARETINA

$$
\begin{aligned}
& =\frac{\text { Rp. } 38 \cdot 400 \cdot 000,00}{0,66} \\
& =\text { Rp. } 633,03 / \mathrm{kend} / \mathrm{km}
\end{aligned}
$$

\section{Biaya bahan bakar minyak (BBM)}

Langkah-langkah perhitungan menggunakan rumus sebagai berikut :

1) Pemakaian $\mathrm{BBM} / \mathrm{kend} / \mathrm{hr}=122$ liter

2) Prodi Kend. = $=1011 \mathrm{~km} /$ hari

3) Harga BBM = Rp. $6 \cdot 650,00$

4) Biaya BBM/kend/hari

$=122 \operatorname{ltr} \times$ Rp. $6.550,00$

$=$ Rp. 799.100,00

5) Biaya $\mathrm{BBM} / \mathrm{kend} / \mathrm{Km}$

= Biaya pemakaian BBM/kend/hari

KM- tempuh/hari

$=\underline{\text { Rp. } 799 \cdot 100,00}$

1011

$=\operatorname{Rp} \cdot 790,40 / \mathrm{kend} / \mathrm{km}$

\section{Biaya ban}

Dalam perhitungan ban, disini merupakan ban yang original depan dan belakang. Dari rumus ini dapat dihitung berapa biaya per $\mathrm{km}$ pemakaian ban dan pembelian ban baru.

Langkah-langkah perhitungannya menggunakan rumus sebagai berikut :

a. Ban depan

1. Daya tahan ban $=55.000 \mathrm{~km}$

2. Prodi kend. $=1011 \mathrm{~km}$

3. Harga ban/buah $=$ Rp. $700 \cdot 000,00$

4. Biaya ban $/ \mathrm{kend} / \mathrm{km}$

$$
=\frac{\text { jumlah ban } \mathrm{x} \text { harga ban/buah }}{\text { Km daya tahan ban }}
$$

$$
\begin{aligned}
& =\frac{2 \times \mathrm{Rp} \cdot 700 \cdot 000,00}{55 \cdot 000} \\
& =\text { Rp. } 25,45 \mathrm{kend} / \mathrm{km} \text { (ban depan) }
\end{aligned}
$$

b. Ban belakang

1. Daya tahan ban $\quad=37.500 \mathrm{~km}$

2. Prodi kend. = $1011 \mathrm{~km}$

3. Harga ban/buah = Rp. $700 \cdot 000,00$

4. Biaya ban $/ \mathrm{kend} / \mathrm{km}$ = jumlah ban $\mathrm{x}$ harga ban/buah Km daya tahan ban $=\frac{2 \times \text { Rp. } .700 .000,00}{37.500}$ $=\operatorname{Rp} \cdot 37,33 \mathrm{kend} / \mathrm{km}$

Total biaya ban

$\mathrm{K}$ = biaya ban depan + biaya ban belakang

$=25,46+37,33$

$=$ Rp. 62,79

\section{Biaya servis kecil}

Langkah-langkah perhitungan menggunakan rumus , sebagai berikut :

1. Servis kecil $=3.000 \mathrm{~km}$

2. Oli mesin $=5$ ltr $\times$ Rp. $150.000,00$

$$
=\text { Rp. } 750.000,00
$$

3. Biaya servis kecil/kend/km $=\underline{\text { Rp. } 750.000,00}$ $3.000 \mathrm{~km}$

$=$ Rp. $250 \mathrm{kend} / \mathrm{km}$

\section{Biaya servis besar}

Langkah-langkah perhitungan menggunakan rumus, sebagai berikut :

1. Servis besar tiap $\quad=20.000 \mathrm{~km}$

2. Oli mesin $=5$ ltr $x$ Rp. $150.000,00$

$=$ Rp. $750.000,00$ 
3. Busi

$$
\begin{aligned}
& =4 \times \text { Rp. } 90 \cdot 000,00 \\
& =\text { Rp. } 360 \cdot 000,00 \\
& =11 \operatorname{tr} \times \text { Rp.7.500,00 } \\
& =\text { Rp. } 7 \cdot 500,00
\end{aligned}
$$

4. Air aki = 1 ltr $\times$ Rp.7.500,00

5. Biaya servis besar/kend $/ \mathrm{km}$

$=$ Oli + busi + air aki

$\mathrm{Km}$ servis besar

$=$ Rp. $750 \cdot 000,00+$ Rp. $360 \cdot 000,00+$ Rp. 7.500,00

$20.000 \mathrm{~km}$

$=$ Rp. $55,87 \mathrm{kend} / \mathrm{km}$

Total biaya servis/kend/km

= biaya servis kecil + biaya servis besar

$=$ Rp. $250+$ Rp. 55,87

$=$ Rp. 305,87 kend $/ \mathrm{km}$

\section{Biaya kampas rem}

Langkah-langkah perhitungan menggunakan rumus :

1. Di ganti tiap $\quad=35.000 \mathrm{~km}$

2. Harga kampas rem $=1 \times$ Rp. $115.000,00$

$$
=\text { Rp. } 115.000,00
$$

Biaya kampas rem/kend/km

$$
\begin{aligned}
& =\frac{\text { Rp. } 115 \cdot 000,00}{35 \cdot 000 \mathrm{~km}} \\
& =\text { Rp. 3,28 kend } / \mathrm{km}
\end{aligned}
$$

\section{Biaya kampas kopling}

Langkah-langkah perhitungan rumus, sebagai berikut :

1. Di ganti tiap $\quad=75.000 \mathrm{~km}$
2. Harga kampes kopling $=1 \times \mathrm{Rp} .350 .000,00$

$$
=\text { Rp. } 350.000,00
$$

Biaya kampas kopling/kend/km

$$
=\text { Rp. } 350.000,00
$$

$75.000 \mathrm{~km}$

$$
=\text { Rp. } 4,67
$$

kend $/ \mathrm{km}$

\section{Biaya Retribusi}

Biaya retribusi berdasarkan hasil wawancara dengan pemilik angkutan umum adalah sebesar Rp. 300.000,00/tahun, sehingga apabila dibagi rata-rata operasional kendaraan per tahun, maka diperoleh nilai Rp. 833,33/hari. Adapun langkah-langkah untuk menghitung biaya retribusi $/ \mathrm{km}$ perhitungannya menggunakan rumus, sebagai berikut :

Biaya retrisbusi/tahun $=$ Rp. $300.000,00$

1) Biaya retrisbusi $/$ tahun $=\frac{\text { Rp. } 300.000,00}{30 \text { hari } \mathrm{x} 12 \mathrm{bln}}$

$=$ Rp. 833,33/hari

2) Biaya retrisbusi $/ \mathrm{kend} / \mathrm{km}$

= Biaya Retribusi / hari

Prod. Kend-km/hari

$$
\begin{aligned}
& =\frac{\text { Rp. 833,33/hari }}{702} \\
& =\text { Rp. } 1,18 / \text { kend } / \mathrm{km}
\end{aligned}
$$

\section{Biaya perpanjangan STNK}

Langkah-langkah perhitungan menggunakan rumus sebagai berikut :

1. Prodi Kend. $-/ \mathrm{km} / \mathrm{tahun}=60.660 \mathrm{~km}$

2. Biaya pajak /tahun = Rp. $2 \cdot 200 \cdot 000,00$ 
3. Biaya pajak/kend/km

= biaya $\mathrm{STNK}$ kend/tahun

Prod. Kend-km/tahun

$=\frac{\mathrm{Rp} \cdot 2 \cdot 200 \cdot 000,00}{60.660 \mathrm{~km}}$

$=$ Rp. $36 \cdot 26 / \mathrm{kend} / \mathrm{km}$

\section{Biaya Upah supir}

1. Biaya upah supir / hari

$$
\begin{aligned}
& =\text { Biaya Tiket } x \text { Jumlah Penumpang } \\
& =\text { Rp.900.000,00,- } \text { x } 5 \\
& =\text { Rp.4.500.000,00,- x 30\% } \\
& =\text { Rp.1.350.000,00,- }
\end{aligned}
$$

Dari hasil perhitungan seluruh Biaya Operasi Kendaraan Angkutan Umum Jurusan Palangka Raya

- Pontianak, maka rekapitulasi biaya tersebut dapat di lihat pada tabel sebagai berikut :

\section{Tabel Rekapitulasi Biaya Operasi Angkutan Umum Jurusan Palangka Raya - Pontianak.}

\begin{tabular}{|l|c|}
\hline \multicolumn{1}{|c|}{ Komponen } & Biaya (Rp) \\
\hline Penyusutan (Biaya Tetap) & 633,03 \\
\hline BBM (Biaya Variabel) & 790.40 \\
\hline Ban (Biaya Variabel) & 62,79 \\
\hline Servis Kecil (Biaya Variabel) & 250 \\
\hline Servis Besar (Biaya Variabel) & 305,87 \\
\hline Kampas Rem (Biaya Variabel) & 3,28 \\
\hline KampasKopling (Biaya Variabel) & 4,67 \\
\hline Restribusi (Biaya Variabel) & 1,18 \\
\hline Pajak/STNK (Biaya Tetap) & 36,26 \\
\hline Total & $2.087,48$ \\
\hline
\end{tabular}

\section{Tarif Angkutan Umum}

Dari hasil rekapitulasi pada tabel 4.2 diatas, maka dapat kita analisa perhitungan Tarif Angkutan Umum jurusan Palangka Raya - Pontianak sebagai berikut:

a. Perhitungan total biaya pokok per hari

Langkah-langkah perhitungan sebagai berikut:

1. $\mathrm{BOK} / \mathrm{kend} / \mathrm{km}=$ Rp. $2.087,48$

2. Prod.kend $/ \mathrm{km}=1011 \mathrm{~km} /$ hari

3. Total biaya pokok (Rp/har)

$=$ BOK $\times$ Jarak Tempuh

$=$ Rp. $2.087,486 \times 1011 \mathrm{~km}$

$=$ Rp. $2 \cdot 110.44 / \mathrm{kend} / \mathrm{km} / \mathrm{hari}$

Jadi total biaya pokok per hari angkutan umum adalah sebesar Rp.2.110.44/kend/hari.

b. Perhitungan tarif pokok/org/rit

Langkah-langkah perhitungannya sebagai berikut :

1. Total biaya pokok/kend/hari

$=$ Rp. $2 \cdot 110.44$

2. Jumlah penumpang/hari

$=5$ orang

3. Tarif pokok (Rp/org/rit)

$=$ Total biaya pokok/kend/hari

Jumlah penumpang/hari

$=\frac{\text { Rp. } 2.110 .44}{5 \text { orang }}$

$=$ Rp. 422.089,60/rit/org/hari

c. Perhitungan tarif dasar/org/rit

Tarif dasar merupakan hasil penjumlahan antara pokok dan $10 \%$ dari tarif pokok untuk jasa keuntungan pengelola/pemilik. Adapun langkahlangkah perhitungan adalah sebagai berikut :

1. Tarif pokok

$=$ Rp. 422.089,00/org/rit/hari

2. Tarif dasar

$=\mathrm{Rp}$. Tarif pokok $+($ Tarif pokok x 10\%)

$=$ Rp. $422.089,60+($ Rp. $422.089,60 \times 10 \%)$

$=$ Rp. 464.298,56rit/org/hari 
Jadi tarif dasar angkutan umum jurusan Palangka Raya - Pontianak adalah Rp. 464.298,56/rit/org. Tarif umum yang berlaku untuk angkutan umum di Palangka Raya saat studi adalah Rp. 900.000,00/rit/org.

\section{Analisa Titik Kembali Pokok (Break Even Point Analysis)}

Analisis titik kembali pokok Break Even Point Analysis di singkat BEP adalah suatu analisis yang ditunjukkan terutama untuk perencanaan jangka pendek. Dalam analisis ini dapat diketahui dengan tingkat harga jual dan volume penjualan berapa, pendapatan akan sama dengan biaya.

a. Mencari berapa penumpang yang harus didapat agar terjadi break even point, langkah-langkah perhitungannya menggunakan rumus sebagai berikut :

1. Fixed Cost (Biaya Tetap)

$$
\begin{aligned}
& =\text { Prod.kend } \mathrm{km} \times \text { biaya tetap } \\
& =1011 \mathrm{~km} \times \mathrm{Rp} \cdot 669,29 \\
& =\text { Rp. } 676.658,00 / \mathrm{km}
\end{aligned}
$$

2. Variable Cost (Biaya Variabel)

$=$ Prod.kend $\mathrm{km} \times$ Biaya variabel $/ \mathrm{km}$

$=1011 \mathrm{~km} /$ hari $\mathrm{x}$ Rp. 1.418,19,00

$=$ Rp. 1.433.790,00/hari

Rata-rata jumlah penumpang per hari adalah 5 orang, maka :

$$
=\text { Rp. } 1.433 \cdot 790,00
$$

5

$=\operatorname{Rp} .286 .758,00$

3. $\quad \mathrm{P}$ (harga yang di tentukan)

$=$ Rp. $900.000,00$

4. $\mathrm{S}$ (pendapatan per hari)

$=\frac{\text { Fixed cost }}{\text { P-Variable cost }}$

$=\quad$ Rp. $676.658,256$

$$
\text { Rp. } 900.000,00 \text { - Rp. } 286.758,018
$$

$$
=1,1
$$

$=2$ penumpang

Jadi angkutan umum jurusan Palangka Raya Pontianak minimal harus mendapatkan 1,1 orang/ 1 orang penumpang agar terjadi break even point pada biaya operasional tersebut.

b. Menghitung berapa uang penjualan yang perlu diterima agar terjadi break even point, langkahlangkah perhitungannya dengan menggunakan rumus (3.10) sebagai berikut :

1. Fixed cost (Biaya tetap)

$=$ Prod.kend $\mathrm{km} \times$ Biaya tetap $/ \mathrm{km}$

$=1011 \mathrm{~km} \times$ Rp. 669,29kend $/ \mathrm{km}$

$=$ Rp. 676.658,00/hari

2. Variable cost (Biaya variabel)

$=$ Prod.kend $\mathrm{km} \times$ Biaya Variabel $/ \mathrm{km}$

$=1011 \mathrm{~km} / \mathrm{hari} \times \mathrm{Rp} .1 .418,19,00 / \mathrm{kend} / \mathrm{km}$

$=$ Rp. 1.433.790,00/hari

3. $\mathrm{P}$ (Harga yang ditentukan)

$=$ Rp. $900.000,00$

4. $\quad \mathrm{S}$ (Pendapatan per hari)

$=$ Rp. $900.000,00 \times 5$ penumpang/hari

$=$ Rp. $4.500 .000,00$

Fixed cost

Break Even Point $\quad=\overline{1-\text { Variable cost }}$ S Rp. $676.658,256 \mathrm{kend} / \mathrm{km}$

$=1-$ Rp. $1.433 .790,00 \mathrm{kend} / \mathrm{km}$

Rp. $4.500 .000,00$

$=\quad$ Rp. 993.070,00 


\section{KESIMPULAN}

Dari analisa perhitungan, maka hasil kesimpulan yang dapat kami ambil adalah :

1. Berdasarkan data survei yang dilakukan selama dua minggu maka Total biaya pokok per hari angkutan umum jurusan Palangka Raya Pontianak adalah sebesar Rp. 4.500.000,00 /hari.

2. Tarif pokok angkutan umum jurusan Palangka Raya - Pontianak adalah sebesar Rp. 422.089,60/org/rit/hari tarif pokok ini di dapat dari hasil pembagian antara biaya pokok total per hari.

3. Tarif dasar angkutan umum jurusan Palangka Raya - Pontianak adalah sebesar Rp. 464.298,56rit/org/hari, tarif dasar ini di dapat dari hasil tarif pokok di tambahkan 10\% dari nilai tarif pokok tersebut.

4. Tarif umum angkutan jurusan Palangka Raya Pontianak yang berlaku pada saat penelitian sekarang adalah sebesar Rp. 900.000,00 org/rit.

5. Dengan tarif umum Rp. $900.000,00 \mathrm{org} / \mathrm{rit}$, dan tarif dasar Rp. 464.298,56org/rit maka memberikan keuntungan bagi pengusaha angkutan sebesar Rp. 435.701,44 rit/org atau sekitar $49 \%$.

6. Memberikan keuntungan yang layak bagi pengelola angkutan umum jurusan Palangka Raya - Pontianak.

\section{SARAN}

Saran yang dapat di berikan adalah sebagai berikut :

1. Jumlah armada harus ditambah.

2. Para pemilik atau pengelola angkutan umum jurusan Palangka Raya - Pontianak hendaknya dapat meningkatkan mutu pelayanan kepada penumpang, sehingga dapat memenuhi keinginan pemakai jasa angkutan baik dari segi keamanan, kenyamanan, maupun dari segi ekonomisnya.
Alamsyah, Alik Ansyori, (2005), Rekayasa Lalu Lintas,UMN Press, Malang.

Direktorat Jenderal Perhubungan Darat, (2002) Keputusan Direktur Jenderal Perhubungan Darat Nomor.SK. SK.687/AJ.206/DRJ/2002.

Tentang Teknis Penyelenggaraan Angkutan Umum di Wilayah Perkotaan Dalam Trayek Tetap dan Teratur, (2002).

Direktorat Perhubungan RI, (2002), Keputusan Menteri Perhubungan No.KM 89

Tahun 2002 Tentang Mekanisme penetapan Tarif dan Formula Perhitungan Biaya Pokok Angkutan Penumpang Dengan Mobil Bus Umum Antar Kota Kelas Ekonomi, Departemen Perhubungan Republik Indonesia, Jakarta.

Hobbs,F,D. (1993), Perencanaan dan Teknik Lalu Lintas , Universitas Gajah Mada, Yogyakarta

Miro,Fidel, (2004), Perencanaan transportasi untuk Mahasiswa ,Erlangga,Jakarta.

Munawar, Ahmad, (2005), Dasar-Dasar Teknik Transportasi, Beta Offset, Jogjakarta

Morlok, Edward K, (1978), Pengantar Teknik dan Perencanaan Transportasi, Erlangga, Jakarta.

Nur,Muhammad Alfian, (2008), Evaluasi Tarif Taksi Bandar Udara Tjilik Riwut Palangkaraya,Fakultas Teknik Palangkaraya

Suwardjoko P (2002), Pengelolaan Lalu Lintas dan Angkutan Jalan, ITB Bandung.

\section{DAFTAR PUSTAKA}

